\title{
Cuidado de enfermagem para clientela em hemodiálise: suas dimensões instrumentais e expressivas ${ }^{1}$
}

\author{
Nursing care for the clients in hemodialysis: yours instrumental and expressive dimensions
}

\section{Cuidado de enfermería para clientela en hemodialisis:sus dimensiones instrumentales y expresivas}

Rachel de Carvalho de Rezende', I saura Setenta Porto"l

\begin{abstract}
${ }^{1}$ Trabalho elaborado para o Requisito Curricular Suplementar XIII "Estudo de Temas Emergentes da Prática Profissional", como trabalho de conclusão de Curso de Graduação da Escola de Enfermagem Anna Nery/UFRJ .

Enfermeira pela Escola de Enfermagem Anna Nery/UFRJ (EEAN/UFRJ), Especialista em Enfermagem Médico-cirúrgica pela Escola de Enfermagem Alfredo Pinto/UNIRIO. Email: r_carvalho@oi.com.br.

" Doutora e Pesquisadora do Núcleo de Pesquisa em Enfermagem Hospitalar e Professora Adjunta do Departamento de Enfermagem Médicocirúrgica da EEAN/UFRJ. Email: isaura70porto@gmail.com.
\end{abstract}

\section{RESUMO}

Trata de investigação sobre o cuidado de enfermagem para clientela em hemodiálise. Objetivos: (a) descrever situações de cuidado entre integrantes da equipe-clientela; (b) caracterizar demandas de cuidados da clientela, e (c) analisar dimensões do cuidado nas interações entre integrantes da equipe-clientela. O estudo foi realizado em três hospitais do estado do Rio de Janeiro (dois universitários e um assistencial), no período outubro a dezembro de 2005. A observação participante documentou os cuidados e dezessete integrantes da equipe e clientes-família foram entrevistados. As duas categorias, resultantes de análise de conteúdo, foram as dimensões instrumentais e expressivas do cuidado. A predominância das dimensões instrumentais mostrou o atendimento das demandas biológicas da clientela. A predominância das dimensões expressivas foi destacada como diferencial do cuidado ao facilitar laços para a continuidade do tratamento sem os clientes sentirem-se "partes-de-máquinas". Os resultados demonstraram que dimensões instrumentais e expressivas do cuidado devem ser valorizadas para atender integralmente à clientela sendo que as expressivas devem ser documentadas na prática assistencial e literatura.

Descritores: Cuidados de enfermagem; Relações interpessoais; Empatia; Afeto; Análise e desempenho de tarefas.

\section{ABSTRACT}

It deals with investigation about the care of nursing for clients in hemodialysis. Objectives: (a) to describe situations of care among integrants of the team-clientele; (b) to characterize demands of cares of the clients and (c) to analyze dimensions of the care in the interactions between integrants of the team-clients. This investigation was realized in three hospitals in the estate of Rio de Janeiro - Brazil (two university hospitals and one assistencial), from October to December of 2005. The participant observation registered the cares and seventeen integrants of the team and clientsfamily had been interviewed. The two categories, resultants of content analysis, had been the instrumental and expressive dimensions of the care. The predominance of the instrumental dimensions showed the attendance of the biological demands of the clientele. The predominance of the expressive dimensions was detached as the care differential when facilitating ties for the continuity of the treatment without the customers to feel "part-of-machines". The results had demonstrated that instrumental and expressive dimensions of the care must be valued to attend integrally to the clients where the expressive ones must be registered in the attending practical and literature.

Descriptors: Nurse care; Interpersonal relations; Empathy; Affect; Task performance and analysis.

\section{RESUMEN}

Trata de investigación sobre el cuidado de enfermería para la clientela en hemodialisis. Objetivos: (a) describir situaciones del cuidado entre integrantes de la equipo-clientela; (b) caracterizar demandas de cuidados de la clientela, y (c) analizar las dimensiones del cuidado en las interacciones entre integrantes de la equipo-clientela. A investigación fue realizada en tres hospitales en estado de Rio de Janeiro - Brasil (dos hospitales univesitarios e uno asistencial), de outubro a deciembre de 2005. La observación participante documentó los cuidados y diecisiete integrantes del equipo y clientes-familia habían sido entrevistados. Las dos categorías, resultantes del análisis del contenido, habían sido las dimensiones instrumentales y expresivas del cuidado. El predominio de las dimensiones instrumentales demostró la atención de las demandas biológicas de la clientela. El predominio de las dimensiones expresivas fue destacada como diferencial del cuidado al facilitar lazos para la continuidad del tratamiento sin que los clientes sentíanse "partes-demáquinas". Los resultados habían demostrado que las dimensiones instrumentales y expresivas del cuidado se deben valorar para atender integralmente a la clientela donde las expresivas deben ser documentadas en la práctica asistencial y literatura.

Descriptores: Atencíon de enfermería; Relaciones interpersonales; Empatía; Afecto; Análisis y desempeño de tareas. 


\section{NTRODUÇÃO}

Este estudo explora as dimensões do cuidado de enfermagem presentes na interação entre os integrantes da equipe de enfermagem e clientes, em unidades de hemodiálise. Um trabalho de graduação de revisão da literatura realizado em 2004 mostrou um enfoque técnico do cuidado predominante para essa clientela nas fontes bibliográficas brasileiras consultadas. Além disto, essas fontes eram bem escassas perfazendo um total de apenas 12 obras, entre elas uma monografia de pós-graduação, dez artigos de pesquisa e um livro de enfermagem ${ }^{(1)}$.

O diagnóstico oriundo daquela revisão apontou para uma lacuna do conhecimento, que fez surgir uma necessidade de contribuir para a ampliação da base bibliográfica da área. $O$ que estimulou também a realização desta pesquisa foi à contradição existente entre o conteúdo dessa literatura (um enfoque mais técnico) e o que pensávamos acerca do cuidado, isto é, que existem outras ações de enfermagem diferentes daquelas que apresentam um enfoque predominantemente técnico.

Em apoio à nossa posição, na década de 80 , as pesquisas de enfermagem com orientação tecnicista começaram a declinar para dar lugar aos estudos histórico-sociais, uma tendência que proporcionou um entendimento mais abrangente e contextualizado da evolução profissional ${ }^{(2)}$.

Concordamos que toda situação de cuidado exige o conhecimento técnico-científico. Entretanto, a complexidade tecnológica, que demanda atualização e competência técnica, exige dos integrantes da equipe de saúde questionamentos cotidianos sobre o seu significado, além da compreensão adequada da tecnologia utilizada nas situações de cuidado, sua eficácia em relação à natureza dos problemas e das condições que influenciam na emergência e evolução desses problemas $^{(2)}$. Assim entendida, a técnica deverá manter-se a serviço dos cuidados e não os cuidados a serviço da técnica(3).

Neste sentido, os termos instrumental e expressivo sugiram em obra sobre os quantitativos e qualitativos da assistência de enfermagem aplicados ao sistema social. Naquela obra, as ações da enfermeira denominadas instrumentais ligam-se à situações relativas a problemas externos em direção ao objetivo do grupo. E, as ações da enfermeira denominadas expressivas surgem em situações relativas a problemas internos próprios do relacionamento entre os membros do grupo ${ }^{(4)}$.

Desde então, esses termos foram refinados e reconsiderados em 1991, quando o cuidado de enfermagem passou a ser entendido como um conjunto de procedimentos expressivos e instrumentais $^{(5)}$. Os cuidados instrumentais relacionam-se àquela dimensão que implica em conteúdo predominantemente cognitivo e psicomotor, cujas ações são relativas às necessidades psicobiológicas. Cuidados expressivos compreendem os procedimentos com enfoque predominantemente cognitivo e afetivo, cujas ações estão voltadas para as necessidades psico-sócio-espirituais do paciente ${ }^{(5)}$.

Para efeitos desta pesquisa, estes termos foram adaptados como dimensões instrumentais e expressivas do cuidado, uma vez que o cuidado é indivisível em sua implementação. Assim, essas dimensões encontram-se entrelaçadas sendo essa, uma das maneiras de investigamos o cuidado, enquanto um exercício de compreensão sobre sua natureza, que permite a exploração partir de suas partes componentes.

Em reforço à identificação da lacuna de conhecimento identificada naquela revisão realizada, o cuidado acontece no âmbito da interação entre seres humanos que cuidam e são cuidados $^{(6)}$. Esse acontecimento interativo pressupõe comportamentos e habilidades pessoais/profissionais que extrapolam uma intencionalidade meramente técnica/instrumental, atingindo um outro patamar capaz de responder à demandas mais afetivas/expressivas da clientela.

Considerando o exposto, uma questão orientou as buscas da investigação realizada, a saber: Como se configura o cuidado de enfermagem para a clientela em processo de hemodiálise? Nesta configuração incluem-se as dimensões presentes no cuidado de enfermagem, ou seja, as dimensões instrumentais e expressivas entrelaçadas na prática assistencial.

Assim, optamos por adotar a predominância relativa a estas dimensões, uma vez que a natureza interativa do cuidado nunca é pura, ou seja, o cuidado não exprime apenas dimensões puramente instrumentais ou expressivas num dado momento. Duas ou mais dimensões estão sempre presentes numa interação determinada pela realização do cuidado. Neste sentido, a concepção de cuidar envolve muito mais que atos. Assim, "cuidar é mais que um ato; é uma atitude. (...) um momento de atenção, de zelo e de desvelo. Em outras palavras, uma atitude de ocupação, preocupação de envolvimento afetivo, que pertence à atitude do cuidado, que se encontra na raiz do ser humano, por ser ele o próprio cuidado singular e na sua essência"(7).

Partindo destas posições, o objeto de estudo explorado nesta investigação é o cuidado de enfermagem frente às demandas da clientela, em unidades de hemodiálise. Para configurar este cuidado foram estabelecidos os seguintes objetivos de pesquisa: (a) descrever as experiências de cuidado entre os integrantes da equipe de enfermagem e essa clientela; (b) caracterizar as demandas de cuidado dessa clientela; (c) analisar as dimensões do cuidado encontradas durante nas interações entre integrantes da equipe $e$ clientela/família. 
Esta pesquisa pode contribuir para a construção do saber nas áreas de Enfermagem Hospitalar e Enfermagem em Nefrologia, além de trazer reflexões baseadas na prática assistencial pesquisada, que podem proporcionar novas reflexões sobre a natureza do cuidado de enfermagem. Ela pode contribuir também para a demonstração de como o cuidado técnico é uma parte relativamente pequena do cuidado prestado pela equipe de enfermagem para essa clientela, considerando-se todas as suas dimensões presentes. A relação entre esses dois parceiros do cuidado, o que cuida e o que é cuidado, apresenta tanto a realização de atos objetivos, como de imponderáveis objetivados através de toques e olhares, no carinho presente na interação, na conversa e na amizade cultivada.

\section{TRAJETÓRIA METODOLÓGICA: A EXPLORAÇÃO DE UMA REALI DADE EMPÍ RI CA}

Esta é uma pesquisa com abordagem qualitativa, que também se vale de técnicas quantitativas. Numa pesquisa com esta abordagem, os participantes expõem nas suas falas muito mais do que respostas em simples questionários demarcatórios, podendo proporcionar detalhes que, muitas vezes, não estão nem nos prontuários dos clientes, nem nas produções cientificas $^{(8)}$. A pesquisa qualitativa é caracterizada como a tentativa de uma compreensão detalhada dos significados e características situacionais apresentadas pelos entrevistados ${ }^{(9)}$.

Este estudo foi realizado no estado do Rio de Janeiro, em dois hospitais universitários e em um hospital assistencial, no período entre outubro e dezembro de 2005. Seus participantes foram os integrantes da equipe de enfermagem e os clientes/família, em unidades de hemodiálise. Os resultados da aplicação de questionário com alguns dados sócio-demográficos junto a onze integrantes da equipe mostraram que a maioria é de mulheres $(72 \%)$, com a idade média de 30 anos, casadas $(45 \%)$, sendo $36 \%$ de solteiras(os). Desses integrantes, $45 \%$ têm um filho e $54 \%$ não tem filhos. Com relação a profissão, $54 \%$ são técnicos, $28 \%$ são auxiliares de enfermagem e $18 \%$ são enfermeiros. A carga horária de trabalho de plantonista de $82 \%$ dos integrantes é de 12 horas de trabalho por 60 horas de folga e descanso e $18 \%$ trabalham de diariamente pela manhã.

Quanto aos seis clientes entrevistados destacase uma maioria com idade entre 30 e 40 anos. Quanto ao sexo, 83\% é do feminino e $66 \%$ deles têm estado civil de casado sendo $33 \%$ de solteiros, $77 \%$ têm filhos sendo que a maioria tem apenas um filho. O grau de instrução é de $15 \%$ para o ensino fundamental completo e ensino superior respectivamente. $\mathrm{E}$, de $35 \%$ para o ensino fundamental incompleto e ensino médio respectivamente; $67 \%$ têm renda familiar de 1 a 3 salários mínimos e $33 \%$ não tem salário. A maioria destes clientes teve acesso ao diagnóstico há mais de três meses, mas alguns já estão há quatro anos em tratamento.

Os cenários de estudo foram as unidades de hemodiálise de dois hospitais universitários públicos, um estadual e outro federal; e um hospital assistencial público federal localizados na cidade do Rio de Janeiro. Os hospitais universitários têm 39 auxiliares e técnicos e seis enfermeiros e o hospital assistencial tem 24 auxiliares e técnicos e seis enfermeiros. Ambos os hospitais universitários apresentam um ambiente com refrigeração por ar condicionado, televisão e uma média de 4 poltronas para seus clientes. Os dias de atendimento ocorrem nas $2^{\text {as }}, 4^{\text {as }}$ e $6^{\text {as }}$ feiras para um grupo de clientes e $3^{\text {as }}$ e $5^{\text {as }}$ feiras e sábados para o outro grupo. As máquinas de hemodiálise de um dos hospitais universitários são mais modernas que as do outro, possivelmente pela escassez de verbas governamentais. O ambiente do hospital assistencial apresenta refrigeração, 10 leitos e não tem televisão.

A principal diferença observada entre os três hospitais foi a rotina de atendimento. Os hospitais universitários espaçam as sessões para uma preparação mais calma dos clientes e das máquinas e um descanso dos integrantes da equipe entre elas. $\mathrm{O}$ fluxo de clientes do hospital assistencial é muito maior, pois recebe clientes internados e externos. Uma particularidade a ser destacada é o acolhimento dos clientes pelos próprios integrantes das equipes, que é o diferencial em cada um dos hospitais. As diferenças identificadas nesse acolhimento, uma parte do cuidado de enfermagem, nas três unidades estudadas traz a marca da interação pessoa a pessoa, e não depende do ambiente.

Atendendo aos princípios éticos da pesquisa, tal como se encontram na Resolução n. $\underline{196 / 96}$, do Conselho Nacional de Saúde, o projeto desta pesquisa foi encaminhado aos Comitês de Ética em Pesquisa dos três hospitais escolhidos para a coleta de dados sendo aprovado em todos eles, através das autorizações Memo n. o 956/05, CEP (...) n.o 21/05 e documento sem numeração, além do registro de protocolo no SISNEP/MS sob o n. ${ }^{\circ}$ 0088.0.197.22605. A garantia do sigilo e anonimato foi comunicada aos participantes da pesquisa, através de explicação sobre a natureza da pesquisa - seus objetivos, seus instrumentos de coleta de dados (observação participante e entrevista) e usos de seus resultados e ainda, da possibilidade de se retirarem da pesquisa sem nenhum prejuízo para eles. Depois desta explicação, todos os participantes assinaram o Termo de Consentimento Livre Esclarecido e, participaram até o final da realização da pesquisa.

Esta pesquisa adotou três tipos de instrumento para coleta de dados, aplicados na seguinte ordem: (1) observação participante, com registro em diário de campo, que teve a finalidade de captar a realidade dos cuidados prestados pelos integrantes da equipe 
de enfermagem. Ela foi adotada como estratégia complementar, pois se partiu da posição de que o observador estabelece uma rede de relações com os observados e participa das ações ${ }^{(10)}$; (2) questionário sobre alguns dados sócio-demográficos foi utilizado como forma de obter informações mais detalhadas sobre o grupo estudado, através dos dados como grau de instrução, profissão, carga horária semanal de trabalho, salário, estado civil e sexo; e, (3) entrevista livre com os integrantes da equipe de enfermagem das unidades de hemodiálise, com a finalidade de abrir um espaço para que eles se posicionassem acerca das dimensões técnicas/instrumentais e não técnicas/expressivas do cuidado detectadas durante a execução de seus cuidados junto à clientela.

A coleta de dados foi realizada por uma das pesquisadoras. Sua entrada no campo de pesquisa ocorreu por meio de sua apresentação aos integrantes da equipe das unidades de hemodiálise. Nesta ocasião, ela explicou o motivo do estudo e a finalidade de sua permanência no local esclarecendo as possíveis dúvidas que surgiram. Em cada hospital, a observação participante durou 16 horas perfazendo um total de 48 horas, e seus registros foram realizados em diário de campo.

As entrevistas livres foram realizadas após a observação de cada situação de cuidado, sendo gravadas em fita magnética cassete. Elas se basearam no cuidado ofertado permitindo que o entrevistado explicasse suas ações/reações no momento em que o cuidado ocorreu. Após a transcrição e correção das entrevistas foi adotado um código para identificá-las: ENT. entrevista, enf. para enfermeiro, aux. para auxiliar, pac. para paciente e Inst. A, Inst. B e Inst. C para os hospitais A, B ou C.

O tratamento dos dados foi realizado através da análise de conteúdo, do tipo análise categorial/temática. O corpus de dados foi constituído pelos registros do diário de campo e pelas transcrições das entrevistas. Os conteúdos do diário de campo foram recortados em temas sendo posteriormente quantificados. Os mesmos temas guiaram os recortes das entrevistas. Os temas foram agrupados e reagrupados tomando por base as categorias construídas em trabalho de revisão da

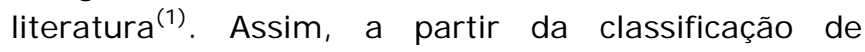
elementos constituídos a partir de critérios previamente estabelecidos ${ }^{(11)}$, as duas categorias empíricas organizadas foram: as dimensões instrumentais do cuidado de enfermagem, com um predomínio dos aspectos técnicos e as dimensões expressivas, com predomínio dos aspectos afetivos e sensíveis.

Para apresentar estas categorias adotou-se a indicação das freqüências de temas encontrados na observação de 60 situações nas dimensões instrumentais do cuidado e de 50 situações nas dimensões expressivas do cuidado. Nas transcrições das entrevistas foram encontrados quatro recortes voltados para as dimensões instrumentais do cuidado e onze recortes classificados nas dimensões expressivas do cuidado. A análise e interpretação dos resultados foram realizadas à luz de fontes bibliográficas presentes nesta pesquisa e naquela revisão de literatura(1).

\section{ANÁLI SE E I NTERPRETAÇÃO DOS RESULTADOS}

\section{Categoria I. Dimensões instrumentais do cuidado de enfermagem}

Nesta categoria foram agrupadas 60 situações de cuidado observadas e registradas em diário de campo. Nessas situações, os clientes foram envolvidos 74 vezes, enquanto que os integrantes da equipe de enfermagem envolveram-se 83 vezes. Houve um desequilíbrio entre a freqüência de temas encontrados na observação participante (138 recortes) e a freqüência de temas nas entrevistas livres (04 recortes).

$\mathrm{Na}$ rotina vivenciada pelos integrantes da equipe e clientela em processo de hemodiálise, os clientes eram ou não acompanhados por familiar. A primeira atividade realizada era a verificação de seu peso com o objetivo de detectar o ganho acumulado entre uma sessão e outra. Assim, os integrantes da equipe podiam avaliar a ingestão hídrica e alimentação dos clientes em casa e verificar sua adequação aos padrões estabelecidos para uma vida com riscos minimizados $^{(12)}$.

Além disso, a comparação entre o peso seco e o peso apresentado pelos clientes no momento de sua entrada na unidade era essencial para estabelecer a perda necessária na hemodiálise e fundamentar suas orientações para determinados clientes. Nessa etapa, o cuidado consiste em calcular exatamente o peso, para que jamais esteja acima ou abaixo do que é real, com a finalidade de evitar diversas complicações durante a sessão de hemodiálise ${ }^{(12)}$.

Posteriormente, os clientes eram acomodados em cadeiras ou leitos, sendo verificada sua pressão arterial, para base de comparação durante toda a hemodiálise. Então, a punção da fístula artériovenosa ocorre com a precaução de localizá-la exatamente. Por isto, às vezes, os integrantes da equipe de enfermagem solicitavam a ajuda ao próprio cliente quando iam puncionar a fístula, pois eles sabiam indicar os locais para punção. Existiam também clientes internados, com urgências que necessitam maior atenção da equipe e, algumas vezes, de assistência médica, durante o procedimento de punção ou durante a realização da hemodiálise.

Em situações extra-rotina, como perda da fístula ou nova fístula artério-venosa, os integrantes da equipe procuravam dar atenção ao procedimento observando a manutenção do fluxo sangüíneo suficiente para as horas totais da hemodiálise. Neste 
sentido, é importante para equipe de enfermagem dominar o procedimento de punção artério-venosa, já que a depuração de uréia pode ser menor, caso a punção não esteja adequadamente realizada, o que prejudica a finalidade da hemodiálise $\mathrm{i}^{(13-14)}$.

Os integrantes da equipe agiam nas intercorrências com as técnicas necessárias e também, com conversas com a clientela para orientála à respeito dos possíveis distúrbios orgânicos causados pela falta de atenção à dieta e ao modo de vida diferencial para sua doença, a partir do relato de suas queixas de excesso de peso, tais como "tonteiras", sensação de "corpo pesado", edema nos membros inferiores, indisposição, falta de ar e ainda, dores causadas pela localização da fístula no braço dificultando a escrita, pegar objetos e até, por vezes, inutilizando a mão. Essas queixas são problemas colaborativos ou complicações potenciais ao tratamento da hemodiálise ${ }^{(13)}$.

Por fim, havia a troca de curativos e o desligamento da máquina. Como parte do cotidiano de uma sessão de hemodiálise, também ocorriam algumas intercorrências ou complicações dos clientes ou dúvidas acerca delas quando eles iniciavam o tratamento, tais como: desequilíbrio hídrico, desequilíbrio eletrolítico (hiponatremia e hipopotassemia), náuseas/vômitos; reações à transfusão, vazamento do líquido dialisador, rompimento do acesso vascular, coagulação, infecção, febre/calafrios, hipertensão/hipotensão, hipertemia, anemia, cãibras e outros ${ }^{(12)}$. Elas evidenciavam o conhecimento técnico-científico dos integrantes da equipe.

Por exemplo, as cãibras ocorriam quase sempre, quando os clientes eram submetidos à ultrafiltração muito rápida para remoção do excesso de líquido ingerido no intervalo dialítico. Essa correção é feita por administração de uma solução salina isotônica e a ação de enfermagem consiste na aplicação de calor no músculo afetado, flexão dos dedos sobre o dorso do pé ou pedir ao cliente para fazer pressão sobre a planta do pé. A hipotensão é uma problemática aguda durante as sessões. Para corrigi-la e melhorar o desconforto sentido pelo cliente, deve-se aumentar a concentração de sódio como solução tampão e diminuir a temperatura do líquido de diálise ${ }^{(12)}$.

Ainda se destacaram as orientações dos integrantes da equipe para os clientes durante a hemodiálise, como a orientação sobre sua permanência nas sessões nos dias marcados, mesmo quando moram longe do hospital. Orientavam inclusive sobre a busca de outras clinicas mais próximas de suas casas, se fosse necessário. Mas também, ocorreram orientações voltadas para a atenção relacionada com a fístula e manutenção do peso em casa. Os integrantes da equipe justificaram essas orientações confirmando os dados derivados da observação participante. Neste sentido, a entrevista de um deles destacou:
Eu acho importante, lógico! Porque, é uma coisa que eu gosto de fazer. Eles cuidam do braço, da fistula deles. (...) Ainda mais, como é primeiro dia dele, explicando o cuidado que deve fazer, para aceitar o tratamento. (...) Então, às vezes, [ele] já vem mal-humorado, não aceita. Então, isso é muito importante, a gente chegar (...), conversar um pouquinho com o paciente. Porque às vezes, eles não querem fazer a hemodiálise no dia. Então, é bom chegar e conversar. A gente tem mais é que ouvir o paciente, mostrar para ele [o que] é importante para aquele momento. Por exemplo, quando o cliente chegou, ele não queria puncionar pela fístula nova. Mas, com a ordem do médico tinha que ser feito, pois estava no tempo certo. Então, foi compreendido e feito [e falei]: "Viu? Não aconteceu nada até agora! Correu tudo bem!" (ENT aux. 02. Inst. C).

O próprio cliente enfatizou este aspecto em algumas entrevistas:

(...) A questão do ensinamento é valida sim. Ainda mais no meu caso, [porque] sou técnica de enfermagem. (...) Embora trabalhe aqui dentro, (...) fiquei avoada, ainda mais nessa situação. Eu nunca entrei numa "nefro". Meu setor é totalmente separado disso aqui. Então, a gente "cai de páraquedas". Assim, (...) a gente está inerte, não sabe nada do que se passa aqui. E isso [ensinamento] é importante, para a gente tentar ficar e passar dias melhores (ENT pac. 08 Inst. C).

A observação desses cuidados aproximou-se da literatura utilizada, que os fundamentou. Mas, outras situações distantes da literatura envolveram clientes externos que necessitavam de cuidados além dos prestados pela equipe de enfermagem. Assim, tornou-se necessário chamar um médico ou encaminhar o cliente para outro setor, no qual ele pudesse ser atendido adequadamente.

O movimento desta categoria mostrou que a dimensão predominantemente instrumental do cuidado ocorreu como espera-se que ocorram procedimentos técnicos, orientações específicas dirigidas ao estado biológico/clínico desta clientela e encaminhamentos realizados quando necessários. Assim, pode-se depreender que os dados apresentados acompanham o que está estabelecido na literatura.

\section{Categoria II . Dimensões expressivas do cuidado de enfermagem}

Nesta categoria foram agrupadas 50 situações de cuidado observadas e registradas em diário de campo. Nestas situações, os clientes foram envolvidos 73 vezes, enquanto que os integrantes da equipe de enfermagem envolveram-se 62 vezes. Foram ressaltadas diversas formas de abordagem afetiva dos integrantes da equipe de enfermagem voltadas para a clientela em processo de hemodiálise, sendo também fornecidas explicações dos próprios participantes sobre suas ações nas entrevistas livres 
realizadas. Foram encontrados 60 recortes da observação participante e nove recortes de entrevistas livres.

$\mathrm{Na}$ dimensão predominantemente expressiva do cuidado, as manifestações corporais foram observadas como forma de comunicação entre integrantes da equipe de enfermagem e os clientes. Através da leitura de expressões faciais percebia-se muitas vezes, a problemática sentida ou vivida pelo outro, sem necessidade do uso de palavras. Essas expressões mostraram-se freqüentemente nas situações de acolhimento, durante o momento da chegada desses clientes tentando transmitir carinho, segurança e troca de sensações ${ }^{(15)}$. Existiram também expressões faciais compatíveis com dor, que os clientes expressaram durante o procedimento da punção artério-venosa.

Um dos destaques da observação participante foi o sorriso, com o qual os integrantes da equipe de enfermagem e os clientes expressam que estão felizes em se rever. Muitas vezes, esse sorriso é buscado pela equipe de enfermagem, para tornar o momento menos desagradável para o cliente ${ }^{(15)}$. Uma das entrevistas destaca essa estratégia:

Faço com todos eles, desde quando me formei e eu me sinto bem. E faço também no outro hospital. Porque, isso descontrai o paciente, deixa o paciente (...) sorrindo. E um sorriso para mim é tudo! Quando um paciente está sorrindo, esquece todo o trauma que ele tem, toda a preocupação com a doença dele, melhora o estado dele na máquina, no leito... Por isso, eu sempre brinco, eu puxo um sorriso deles, para eles descontraírem dos problemas. Porque, é muito difícil estar numa máquina, num leito, longe da família, entende?! (ENT aux.04 Inst. B).

Por outro lado, o cliente também concorda sobre o efeito da provocação do sorriso:

Eu acho maravilhoso, porque eles levantam o astral da gente, não deixam abater (...), entende? A gente ri, brinca e quando o negócio fica feio, a gente fica triste. Mas aí, ele alegra de novo. Isso é muito maravilhoso! (ENT pac.06 Inst. B).

O contato corporal entre cliente e o integrante da equipe e, até mesmo, com um parente, estiveram presentes sendo observados beijos, abraços e toques de mão. Eles manifestavam um conhecimento mútuo prolongado, que proporcionou a existência de um vínculo afetivo(15). O toque também teve a intenção de acalmá-los, distraí-los da dor da punção e relaxálos. A própria equipe ressalta que a confiança adquirida em determinado profissional é comum pelos anos de convivência mútua. Segundo alguns integrantes da equipe, isto contribui para o prosseguimento do tratamento:

Eu acho assim (...), a pessoa já tem idade. Então, praticamente está quase no seu fim [risos]. A pessoa precisa mais de carinho, cuidado mais especial para elas. Eu acho que sim, esse cuidado é melhor para eles. Eles quase não entendem (...) eles entram na máquina e perguntam por que isso ou para que isso? Eles não entendem (...) [risos]. Na verdade, não melhora não, quando eu faço isso, a parte clínica, sabe?! Mas, eles se sentem mais acolhidos, com mais carinho, com certeza! (ENT aux. 05 Inst. ...).

Normal, esse tratamento é normal. Eu convivo com os pacientes daqui, mais do que com minha família. Passo mais tempo aqui com eles. A maioria é muito problemática. Então, eu reparo naquele que precisa mais e procuro sentar e conversar com ele. (...) Vou lá converso, uso uma palavra tentando levantar a moral, quando está triste (ENT aux. 06 Inst. B).

$O$ toque assume muitas funções durante 0 cuidado. A literatura justifica que para ter um bom relacionamento entre clientes e integrantes da equipe de enfermagem há a necessidade de um ambiente de confiança, no qual o afago, o aperto de mão, um olhar carinhoso e amigo estão incluídos ${ }^{(14-15)}$. Estas são características que oferecem apoio real aos clientes em processo de hemodiálise. A máquina não faz o cuidado que o ser humano é capaz de fazer: preocupar-se com o próximo ${ }^{(16)}$.

Estes aspectos estão expressados na atenção que a equipe de enfermagem tem com essa clientela em processo de hemodiálise, como vemos na fala de um deles:

(...) Dou atenção também a eles, porque são pacientes que requerem muito cuidados. Têm muitos que são independentes, têm outros que são dependentes. Então, (...) a gente tem que ter uma maior atenção a eles. Porque não é fácil ser cliente renal crônico. Então, requer mais atenção; uns até conseguem levar legal, mas outros não, por que já vai para parte psicológica do paciente, né?! (ENTaux.03 e pac.10- Inst. C).

A fala é uma outra forma de expressar afeto, como uma continuidade do cuidado. Através dela, ambos os personagens envolvidos numa situação conseguem comunicar-se e passar informações e sensações que estão sendo vivenciadas no momento ${ }^{(17)}$. Às vezes, existe a necessidade de falar com outras pessoas, como forma de extravasar um problema. As falas facilitam as comparações com casos já vivenciados pelo profissional destacando-se a chance de vida do cliente, sua aceitação de ser um cliente renal crônico dependente de uma máquina. As falas dos integrantes da equipe também tiveram o objetivo de distrair o cliente das longas horas de hemodiálise, ainda que tivessem por finalidade, estabelecer um elo de confiança entre o profissional e o cliente.

Essa forma de comunicação como uma das mais importantes para o andamento da interação entre equipe de enfermagem e os clientes. Os membros da equipe devem ser capazes de não só conhecer sua clientela, mas também os familiares e amigos que o cercam, no momento tão crítico como o de uma doença crônica. Ao entrar em contato com todos os profissionais facilita o desfecho do tratamento e a 
permanência deles nas sessões favorecendo um vinculo terapêutico ${ }^{(18)}$.

Algumas das entrevistas de profissionais confirmam a análise realizada:

Sim, é normal. Às vezes, elas têm um assunto que conversam com a gente. Eu sempre converso, entende?! Não fico assim ... sabe?! Coloco na máquina ... mexe na máquina ... não fico só no serviço de enfermagem propriamente dito, por exemplo. Sempre que eles tem alguns problemas, a gente conversa, dá nossa opinião para eles, entende?! Eu sinto que eles saem daqui melhor. Eles saem relaxados (ENT. aux.04 com pac.08- Inst. A).

Acredito, que isso ajuda. Eles ficam muito tempo, quatro horas. (...) Aí, eles ficam olhando a gente, conversam, (...) porque ficar numa cadeira de hemodiálise por quatro horas é muito monótono. Então, se eu sentar lá e conversar, vai passando o tempo (...). Então, quando eles notam 'já tem tantas horas!' Então, acho bom! (ENT. aux.04 com pac.08Inst. A).

Procuro conversar sempre, dar atenção que eles precisam. Principalmente porque a hemodiálise em si são quatro horas. O paciente precisa de uma atenção maior. Já tem um problema, vem com uma carga pesada (...) Tá descobrindo a pouco tempo que virou renal crônico (...) Eles precisam dessa atenção. Quando dá tempo, você tem tempo, (...) quando tem, eu faço isso contínuo (ENT. aux.06 e pac.08Inst. C).

A última temática desta categoria é a de interação espontânea entre cliente e integrante da equipe de enfermagem. No momento em que os clientes chegam ou durante a realização da hemodiálise, eles conversam sobre Os acontecimentos cotidianos de suas vidas, de novelas, da preocupação que tem com outros colegas de sessão, entre outras coisas. Eles também conversam com o familiar/parente, durante o momento da hemodiálise.

A interação espontânea que ocorre entre os clientes e os integrantes da equipe de enfermagem agrega, por vezes, outros clientes, principalmente quando existe uma ação de orientação que a equipe procura desenvolver à respeito do peso apresentado pela clientela, para que ela passe bem após a hemodiálise, dos comentários dos clientes a esse respeito, da questão do carinho que um tem pelo outro ao chegarem para a sessão ou ao saírem dela, quando conversam sobre assuntos diversos só para que eles se sintam mais à vontade, da aproximação física aos clientes apenas para conversarem sobre seus problemas familiares ou de algo que sintam que o está perturbando naquele momento. Essas ações surgem pela própria iniciativa da equipe em se preocupar e interessar por sua clientela, em acreditar que esta aproximação vai fazer bem a ela.

A literatura confirma esta análise apontando que a interação com o cliente faz com que seja possível o crescimento de um relacionamento de confiança, que permite que os clientes sintam-se mais seguros ${ }^{(6)}$. Assim ao expressarem seus sentimentos, dúvidas, anseios e desejos, os integrantes da equipe de enfermagem podem ajudá-los a entender o processo de sua doença, dar orientações e fortalecer a clientela para passar por esse momento em suas vidas.

A Enfermagem deve ter a capacidade de decodificar os diversos sinais enviados pelos seus clientes, para traçar um plano de cuidados adequado a cada situação presente nos diversos momentos em que estão lidando com essa clientela especial. A Enfermagem é responsável por iniciar esse vínculo fornecendo as informações adequadas para a orientação da clientela sobre os aspectos técnicos, prevenindo sua ansiedade e evitando complicações decorrentes da hemodiálise ${ }^{(13)}$.

Algumas entrevistas demonstram através das falas dos integrantes da equipe, o que eles pensam a esse respeito:

Essa interação é de muito tempo que estou aqui e eles dialisam juntos. Faz dois anos que estou aqui e isso faz com que conheça suas famílias, eles e seus problemas. Com isso faz com que saibamos mais dele. Por exemplo, uma delas está com HIV. E isso faz com que se sintam melhor ao termino da sessão, com certeza. (ENT. aux.06 com pac. 10 - Inst. A).

Normal (...) esse tratamento é normal. (...) Eu convivo com os pacientes daqui, mais do que com minha família. Passo mais tempo aqui com eles (...). A maioria é muito problemática. Então, eu reparo naquele que precisa mais e procuro sentar e conversar com ele. (...) Vou lá, converso, uso uma palavra tentando levantar a moral, quando está triste. Entendendo que é triste ficar quatro horas sentado nessa máquina aí.. No nível da parte humana, acredito que saiam melhor, sim. No nível da clínica, depende da diálise que faz (...) Como eu vou dizer?! Com mais força ou não (...) Tem uns que saem passando mal, outros não. Isto depende. Mas no nível geral, isso ajuda (...), ajuda bastante. Um bom papo durante quatro horas de diálise, se diverte, distrai, a hora passa mais rápido. [risos] (ENT. aux.06 com pacientes- Inst. B).

Faço sempre, é do meu trabalho (...) Foi o que aprendi (...), a dar atenção. O paciente sente que a gente está olhando e ele fica mais tranqüilo, fica no leito, vê que estamos cuidando. Isso até no dia-a-dia, porque é muito importante. Todo dia ele vê você e vê que o tratou bem. $E$ no dia seguinte, no outro plantão, a mesma coisa. Ele vai pensar o que? Que você é amigo dele. E você acaba arrumando amizade (...) Entre a enfermagem e o paciente. Isto é muito bom para ele! Ele fica satisfeito com isso. Isto é bom para ele, deixa ele mais tranqüilo. Até o fato de você passar a verdade para ele (...): ‘olha eu vou puncionar o senhor ou a senhora, vai $\operatorname{doer}(. .$.$) , mas$ vai ser uma punção só, não vai doer mais (...); vou 
passar um álcool vai arder, mas é para fazer um curativo (...), é para fazer uma assepsia para o senhor ficar bem, ficar melhor'. Entendeu?! Isso é importante para ganhar a confiança deles (ENT. aux.04 e clientes- Inst. C).

Existe uma escassez da literatura sobre a questão não técnica do cuidado de enfermagem em unidades de hemodiálise. Mas, pode-se notar que a interação é o destaque maior dessas ações, o que faz com que o cliente permaneça assíduo nas sessões e se sinta seguro com a equipe que dele cuida. Vale destacar que a conversa é um dos elementos que contribui para a expressão afetiva/sensível de ambos os parceiros do cuidado, o integrante da equipe e o cliente. Até uma conversa franca, na qual a verdade sobre a situação que o cliente está experimentando seja abordada, mesmo que adversa, parece contribuir para que ele aceite melhor o próprio tratamento hemodialítico.

\section{CONSI DERAÇÕES FI NAIS}

Ao abordar como temática o cuidado dos clientes em unidades de hemodiálise foi verificado a presença do uso de tecnologia no cuidado aparente do cotidiano da equipe de enfermagem. Isto foi notado nas rotinas destacadas na primeira categoria, tais como a verificação do peso, da pressão arterial e punção artério-venosa, e das intercorrências durante a sessão de hemodiálise. Cada uma dessas observações esteve presente na literatura abordada para embasamento deste estudo.

Também se verificou a existência de cuidados não-técnicos, uma das categorias em que a literatura buscada abordou muito pouco. Entretanto, na observação participante e nas entrevistas esses cuidados foram muito ressaltados pela clientela e para a equipe de enfermagem. Esse foi um cuidado realizado junto ao cliente, quando os integrantes da equipe ouviram e interagiram durante a sessão de hemodiálise, usando o toque, as palavras, as expressões faciais e os olhares. Tudo isto foi realizado para dar conforto, carinho e incentivo aos clientes para que eles retornassem às sessões de hemodiálise, sendo importantes para garantir sua segurança numa das fases difíceis de sua vida.

Assim, os objetivos do estudo foram atingidos: (a) quando, ao observar as experiências do cotidiano da equipe de enfermagem com os clientes durante algumas sessões, os cuidados realizados nesses momentos foram percebidos e descritos no diário de campo; (b) quando foi caracterizada durante a observação participante e em cada entrevista, a maneira dos integrantes da equipe de enfermagem posicionar-se sobre este cuidado prestado para seus clientes ao citarem as mudanças de comportamento neles, ao se aproximarem durante a punção artériovenosa, as próprias orientações realizadas durante as sessões, as conversas que ajudavam há passar o tempo, o carinho depositado num toque, um olhar, palavras que valorizavam alguma crença que os trouxesse estímulo para reforçar a assiduidade às sessões e enfrentar uma doença renal crônica; (c) as dimensões mais marcantes foram as que englobaram os aspectos afetivos, sociais e espirituais.

Os aspectos afetivos foram documentados no contato íntimo que a equipe de enfermagem mantém com seus clientes/familiares que, muitas vezes, os acompanham durante as sessões de hemodiálise, nos toques, nas abordagens carinhosas, num olhar mais cauteloso e em falas voltadas para melhor desenvolvimento desse cuidado. Estes aspectos tenderam a valorizar a clientela da Enfermagem e diminuir as intercorrências durante as sessões hemodialíticas.

Os aspectos sociais apareceram quando o cliente apontou para a modificação de seu cotidiano alterado devido a doença renal crônica e a necessidade de hemodiálise, através de queixas sobre a perda de seu emprego causada pela necessidade de estar presente quase todos os dias da semana no hospital, a dificuldade de aceitação da doença, que atinge qualquer tipo de classe social, já que o doente renal crônico está presente em qualquer família. Essa problemática social faz com que os clientes muitas vezes abandonem o tratamento, não sigam as orientações dos profissionais de saúde em relação a mudança de estilo de vida e passem muitas vezes, por intercorrências desnecessárias durante o procedimento hemodialítico.

Os aspectos espirituais foram identificados no apego dos clientes à religião, quando procuravam pela cura para sua doença ou a possibilidade de realização do transplante renal. Estes aspectos ainda foram expressados, quando os clientes entendiam a doença como a aceitação de uma 'prova' dada por uma entidade superior, a qual iria também colaborar para eles passarem por esse momento, tão difícil de se lidar. A equipe de enfermagem procedeu nesses casos apoiando suas crenças, sejam elas quais fossem, desde que sejam úteis para um tratamento com bons resultados.

Este estudo, ainda que se constitua em uma abordagem preliminar ao objeto de estudo, demonstra que a literatura existente ainda deixa de alcançar todas as nuances do cuidado da Enfermagem, principalmente aquela relativa às abordagens típicas da dimensão não técnica/expressiva. Ele também confirma que os cenários de hemodiálise são campos de estudo para se valorizar essa atuação dos integrantes da equipe de enfermagem, quando eles se envolvem com os clientes realizando ações que não estão conectados somente com as máquinas operadas durante as sessões de hemodiálise. Talvez outro aspecto ainda a ser investigado refira-se à inconsciência dos profissionais sobre as ações relativas à dimensão expressiva do cuidado também caracterizadas como cuidados de enfermagem. Essa inconsciência decorre 
da falta de percepção de si mesmo como instrumento terapêutico leva a várias conseqüências destacandose as lacunas nos registros de enfermagem, dentre muitas outras possíveis.

O cuidado humanizado ultrapassa o limite da tecnologia e é a abordagem mais adequada para acompanhar clientes portadores de doença crônica, como a insuficiência renal. Ainda que o estudo tenha levantado essas questões em poucas horas de observação e algumas entrevistas, pode se imaginar como a Enfermagem poderia aprimorar seu entendimento sobre as dimensões do cuidado de enfermagem, nas próximas investigações sobre este tipo de clientela, portadora de doenças crônicas, e sua relação com o cuidado de enfermagem.

\section{REFERÊNCI AS}

1. Labriola C, Faria C, Rezende RC, Porto IS. O cuidado de enfermagem para clientes em processo de hemodiálise: uma pesquisa bibliográfica [monograph]. Rio de Janeiro: Escola de Enfermagem Anna Nery/UFRJ; 2004. 20 p.

2. Casanova EG, Porto IS, Figueiredo NMA. O cuidado de enfermagem familiar/exótico na unidade de internação psiquiátrica: do asilar para a reabilitação psicossocial. Esc. Anna Nery. 2006; 10(4):635-45.

3. Colliére MF. Promover a vida: da prática das mulheres de virtude aos cuidados de enfermagem. 1st ed. Lisboa: Lidel Edições Técnicas; 1999.

4. Paim L. Quantitativos e qualitativos da assistência de enfermagem [livre docência]. Rio de Janeiro: Escola de Enfermagem Anna Nery/UFRJ; 1979.

5. Coelho $\mathrm{MJ}$. Os bastidores da assistência de enfermagem: o cliente em risco de vida $e$ a enfermeira na emergência [dissertation]. Rio de Janeiro: Escola de Enfermagem Anna Nery/UFRJ; 1991. 259 p.

6. Figueiredo NMA, Porto IS, Machado WCA. Dama de Negro X Dama de Branco: o cuidado na fronteira vida/morte. Rev. enferm. UERJ. 1995; 3(3):139-149.

7. Boff L. Saber cuidar: ética do humano - compaixão pela terra. 1st ed. Rio de J aneiro: Vozes; 1999.

8. Demo P. Metodologia. 1st ed. São Paulo: Atlas; 1995.

9. Polit FD, Beck CT, Hungler BP. Fundamentos de pesquisa em enfermagem - métodos, avaliação e utilização. Porto Alegre: Artes Médicas; 2004.

10. Minayo MCS. O desafio do conhecimento: pesquisa qualitativa em saúde. São Paulo: Hucitec; 1999.

11. Bardin L. Análise de conteúdo. 1st ed. Lisboa: Edições 70; 1979.

12. Lima EX, Santos I. Atualização de Enfermagem em Nefrologia. 1st ed. Rio de Janeiro: Editora UFRJ; 2004.

13. Reis EMK, et al. Percentual de recirculação sangüínea em diferentes formas de inserção de agulhas nas fístulas artério-venosas, de pacientes em tratamento hemodialítico. Rev. esc. enferm. USP. 2001; 5(1): 41-50.

14. Lima Antonio, Fernandes C. Reflexão sobre o cuidar a partir do cenário da hemodiálise: o corpo como mediador da relação entre aquele que cuida e aquele que é cuidado. O mundo da Saúde. 2006; 30(1): 121-55.

15. Silva LMG, Brasil VV, Guimarães HCQCP, Savonitti BHRA, Silva MJP. Comunicação não-verbal: reflexões acerca da linguagem corporal. Rev Latinoam Enfermagem. 2000; 8(4): 52-8.

16. Cesarino CB, Casagrande LDR. Pacientes com insuficiência renal crônica em tratamento hemodialítico: atividade educativa do enfermeiro. Rev Latino-am Enfermagem. 1998;6(4):31-40.

17. Galvão $M$, Gimeniz $T$ et al. Análise da comunicação proxêmica com portadores de HIV/AIDS. Rev Latino-am Enfermagem. 2006; 14(4): 491-6.

18. Silva MP. Cuidados de enfermagem nos portadores de shunt e fistula artério-venosa. Rev Bras Enferm. 1976;29(2): 81-6.

Artigo recebido em 20.06.08.

Aprovado para publicação em 25.05.09. 